\title{
Differential regulation of leucocyte L-selectin (CD62L) expression in normal lymphoid and inflamed extralymphoid tissues
}

Department of Histopathology, University College

London Medical

School, London

$\mathrm{J}$ M Munro

Division of Nephrology and Department of Medicine, Children's Hospital, the Department of Pediatrics, Harvard Medical School,

Boston,

Massachusetts, USA

D M Briscoe

Department of Immunology, Duke University Medical Center, Durham,

North Carolina, USA

T F Tedder

Correspondence to: Dr J M Munro, Histopathology Department, UCL Medical School, University Street, London WC1E 6JJ.

Accepted for publication 4 June 1996

\author{
J M Munro, D M Briscoe, T F Tedder
}

\begin{abstract}
Aims-To study tissue expression of L-selectin, a leucocyte cell surface molecule that is considered to be involved in adhesion to certain endothelia, particularly in peripheral lymph nodes and during inflammation, and is shed upon leucocyte activation.

Methods-Leucocytes were examined by immunohistochemistry and double immunofluorescence staining in various lymphoid sites and normal and inflamed extralymphoid tissues.

Results-L-selectin was present on mantle zone B lymphocytes in different lymphoid sites, including in intestinal lymphoid tissue, but was absent on germinal centre $B$ cells. Splenic white pulp B cells also expressed L-selectin. The proportion of $T$ lymphocytes expressing L-selectin depended on the site under study, being greatest in peripheral lymph nodes (mean $48 \%$ of $T$ cells positive), and lower in mucosal lymphoid sites and spleen ( 9 and $11 \%$ positive, respectively). Non-lymphocytic L-selectin staining was observed on follicular dendritic cells in tonsils and on macrophages in thymus. L-selectin positive leucocytes were rare in normal extralymphoid tissues, and relatively few were seen in most inflammatory settings. However, in rejecting renal transplants, a higher proportion $(30 \%)$ of leucocytes expressed L-selectin.

Conclusions-Overall, the results indicate how the degree of $L$-selectin expression by leucocytes in particular tissues may reflect a requirement for $L$-selectin expression for entry into those tissues and the activation state of leucocytes once localised there.

(f Clin Pathol 1996;49:721-727)
\end{abstract}

Keywords: cell adhesion, CD62L, inflammation, L-selectin.

Adhesion of leucocytes to endothelium is a key event in lymphocyte recirculation and inflammation. Lymphocyte entry into secondary lymphoid organs is initiated by the binding of lymphocyte "homing" receptors to their respective specific "vascular addressin" counterreceptors located on the luminal surface of lymph node and Peyer's patch high endothelial venules. ${ }^{12}$ One lymphocyte cell surface molecule that supports such adhesive interactions is L-selectin (CD62L, LAM-1, Leu-8, or LECAM-1). ${ }^{3-6}$ L-selectin is a cell surface glycoprotein present on most circulating human lymphocytes. ${ }^{4}$ It contains a terminal C-type lectin domain, a domain homologous to epidermal growth factor, and domains sharing homologies with complement regulatory proteins. $^{3}$

Using an in vitro binding assay developed by Stamper and Woodruff, ${ }^{1}$ the homologous mouse antigen was found to mediate the binding of lymphocytes to peripheral lymph nodes, but not to Peyer's patch high endothelial venules. ${ }^{8}$ Lymphocyte binding to Peyer's patch high endothelial venules was subsequently shown to involve $\alpha 4 \beta 7$ integrin. ${ }^{9}$ Mice possessing a mutant L-selectin gene that results in the complete loss of cell surface expression have been generated by gene targeting. ${ }^{10}$ Lymphocytes from these mice are unable to bind to peripheral lymph node high endothelium. However, previous experimental findings that lymphoma cells which selectively bind to peripheral lymph node high endothelial venules can also spread to Peyer's patches, ${ }^{11}$ and that $F(a b)$ fragments of anti-L-selectin antibody can reduce the migration of lymphocytes to Peyer's patches, ${ }^{12}$ suggest that L-selectin may have a more general contribution to supporting lymphocyte trafficking than just in peripheral lymph nodes. In addition, short term homing experiments using lymphocytes from L-selectin deficient mice demonstrate that L-selectin is involved in regulating lymphocyte homing not only to peripheral lymph nodes, but also to Peyer's patches and spleen. ${ }^{10}$ Overall, experimental evidence suggests that L-selectin plays a major role in lymphocyte homing to peripheral lymph nodes, but may participate to a lesser degree in homing to other lymphoid tissues.

L-selectin is, however, expressed by all types of circulating leucocytes and this molecule also mediates the leucocyte-endothelial interactions, particularly initial rolling adhesion, that occur at extralymphoid sites during inflammation. ${ }^{5613-16}$ Antibodies directed against L-selectin or an L-selectin immunoglobulin Fc region chimera inhibit inflammation in animal models ${ }^{17} 18$ and L-selectin deficient mice have impaired neutrophil emigration into inflammatory sites. ${ }^{10}$ The molecule is shed from leucocytes-for example, myeloid cells, upon activation in vitro. ${ }^{14}$ Lymphocytes also shed L-selectin upon activation. ${ }^{19}$ As $\mathrm{T}$ lymphocytes develop into memory cells, these may again express 
L-selectin. ${ }^{20}$ It is also noted that the state of molecular activation of L-selectin can affect its adhesiveness. $^{21}$

The exact nature of the key endothelial structure that L-selectin binds to is unknown, but seems to be a carbohydrate. L-selectin can bind to the carbohydrate moiety sialyl-Lewis ${ }^{\mathrm{x}}$, which is expressed by endothelium, but as the $\mathrm{L}$-selectin ligand requires sulphation, this indicates that sialyl-Lewis ${ }^{x}$ per se is not the ligand..$^{23}$ The relevant endothelial carbohydrate, whatever it is, rests on protein backbones, such as those of CD34 and GlyCAM$1 .^{24}$ The carbohydrate also seems to be present on mucosal addressin cell adhesion molecule-1 to some degree, ${ }^{26}$ which is consistent with limited binding of L-selectin to mucosal endothelium. The functional carbohydrate ligand for L-selectin is recognised by antibody MECA-79, which shows an upregulation of endothelial expression during inflammation. ${ }^{27}$

Previously, human L-selectin expression has been identified in vivo on mantle zone B cells in lymph node and tonsils. ${ }^{28}$ In the present study we sought to assess the expression of L-selectin by both $\mathrm{T}$ and $\mathrm{B}$ lymphocytes in various lymphoid tissues. The findings included that L-selectin positive $\mathrm{T}$ cells were more likely to be present in peripheral lymph nodes than in mucosal lymphoid tissue, consistent with a particular role for L-selectin in extravasation of lymphocytes in the former tissue. In addition, we assessed inflamed tissues; there was generally little expression of L-selectin by accumulated leucocytes, in keeping with shedding of L-selectin upon cellular activation, although in kidney transplants undergoing rejection, a relatively high proportion of leucocytes, identified as $\mathrm{T}$ cells, expressed L-selectin.

\section{Methods}

Tissues were obtained from either surgical material or postmortem examinations performed within 24 hours of death, during which interval leucocyte antigens are well preserved. ${ }^{29}$ Blocks of tissue along with pellets of isolated peripheral blood leucocytes from four normal donors were snap-frozen in isopentane/liquid nitrogen for cryostat sectioning. The tissues were either lymphoid tissues, or normal or inflamed extralymphoid tissues as follows: peripheral lymph node (five cases); small intestinal or appendiceal lymphoid tissue (six cases); tonsil (five cases); spleen (five cases); thymus (seven cases); normal skin (six cases); normal appendix-muscularis propria and serosa assessed, rather than mucosa (six cases); normal or osteoarthritic synovium (four cases); normal kidney (eight cases); chronically inflamed skin (eight cases); acute appendicitis specimens-muscular wall and serosa (seven cases); rheumatoid synovium (six cases); and kidney transplants showing cellular rejection (eight cases).

Immunohistochemistry was performed on cryostat sections, $6 \mu \mathrm{m}$ thick, using an avidinbiotin method as described previously. ${ }^{30}$
Briefly, after fixation in cold paraformaldehyde, sections were incubated overnight with primary antibodies, and then sequentially exposed to biotinylated horse anti-mouse antibodies and avidin-biotin-peroxidase complex (Vector Laboratories, Peterborough, UK), and diaminobenzidine (Sigma, Poole, Dorset, UK). Subsequently, the sections were counterstained with haematoxylin. Renal specimens were immunostained as described with blocking of endogenous biotin using a kit according to the manufacturer's (Vector Laboratories) instructions. The murine monoclonal antibodies used were: LAM-1-3 (IgG1), ${ }^{13}$ recognising L-selectin; GAP 8.3 (IgG2a; American Type Culture Collection, Rockville, Maryland, USA), recognising all isoforms of CD45; PG-M1 (IgG3, Dako, High Wycombe, UK), anti-monocyte/macrophage $\mathrm{CD} 68^{31}$; T3-4B5 (IgG1, Dako), anti-CD3; B4-78 (IgG1) or AP6-291 (IgM), anti-CD20s; and mouse IgG (MsIgG, Coulter Immunology, Dunstable, UK) as a negative control antibody. Also used was rabbit polyclonal anti-CD3 antiserum (Dako).

All tissues described above were immunostained with LAM-1-3, murine anti-CD3, anti-CD20, and anti-CD68, and parallel sections of normal and inflamed extralymphoid tissues (skin, appendix, synovium, kidney) were additionally stained with GAP 8.3. At least $100 \mathrm{GAP} 8.3$ positive cells were counted in the tissues, the number of LAM-1-3 positive cells counted in the same areas in parallel sections, and the relative proportion (mean and standard error of mean, using standard statistics with $95 \%$ confidence limits) of leucocytes expressing L-selectin calculated. The proportion of neutrophils, identified on morphological criteria, expressing L-selectin in sections of peripheral leucocyte pellets was also assessed.

For double immunofluorescence studies, the sections were fixed in paraformaldehyde as above, washed in phosphate buffered saline (PBS), exposed to $10 \%$ normal goat serum for five minutes prior to two primary antibodies being applied for $16-18$ hours at $4^{\circ} \mathrm{C}$, and washed again. Rhodamine and fluorescein conjugated goat antibodies specific to the relevant primary antibodies (diluted 1 in 20 each in PBS $/ 2 \%$ normal human serum; Southern Biotechnology Associates, Birmingham, Alabama, USA) were applied for 90 minutes at $25^{\circ} \mathrm{C}$. The sections were washed again, mounted in 'Vectashield' (Vector Laboratories), and viewed under a fluorescence microscope with appropriate filters. Controls included incubation with single primary antibodies with subsequent application of secondary antibodies of inappropriate specificity, which did not yield fluorescence. Peripheral blood leucocytes, peripheral lymph node, intestinal lymphoid tissue, spleen, and renal transplants were assessed with a combination of rabbit anti-CD3 and LAM-1-3, and as second layers fluorescein conjugated anti-rabbit immunoglobulin and rhodamine anti-mouse IgG1 antibodies. Peripheral blood leucocytes were assessed with IgM anti-CD20 and LAM- 
1-3, and as second layers fluorescein conjugated anti-IgM and rhodamine labelled antiIgG1. Peripheral blood leucocytes, thymus and renal transplants were assessed with PG-M1 and LAM-1-3, and as second layers fluorescein conjugated anti-IgG3 and rhodamine labelled anti-IgG1 antibodies. Proportions (mean \pm SEM) of cells (at least 50 counted) positive for relevant antigens were determined.

\section{Results}

Of peripheral blood neutrophils, $87.7 \pm 6.7 \%$ expressed detectable L-selectin by immunohistochemistry. Double fluorescence studies of
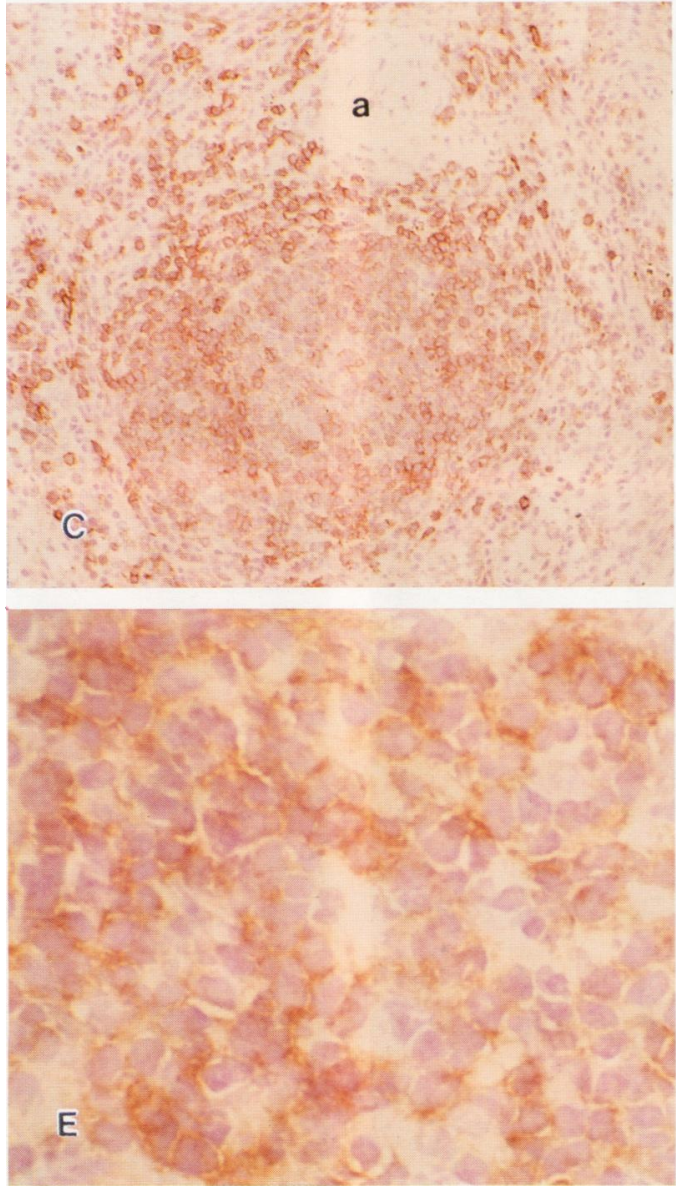

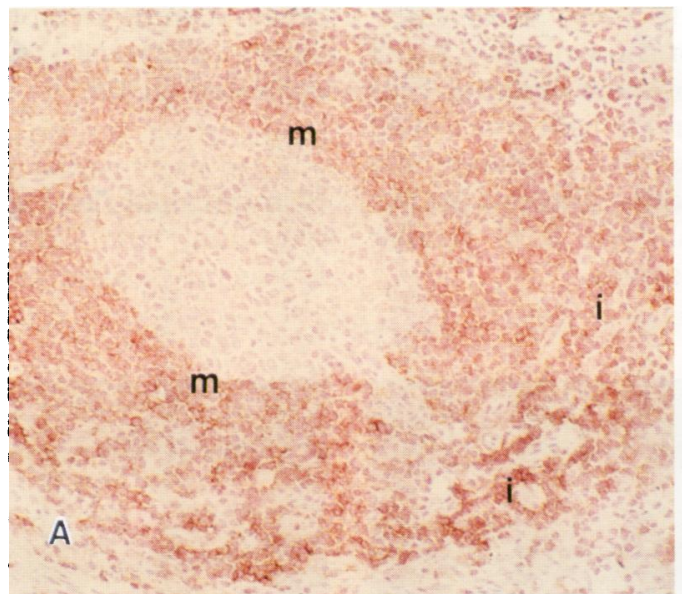

peripheral blood $\mathrm{T}$ cells, $\mathrm{B}$ cells, and monocytes revealed that $64.1 \pm 8.3,76.8 \pm 12.5$ and $73.2 \pm 5.7 \%$ of these, respectively, expressed L-selectin.

L-SELECTIN EXPRESSION IN LYMPHOID TISSUES Within peripheral lymph nodes, follicular mantle zones and germinal centres are well known to be constituted largely of B lymphocytes. Staining of peripheral lymph nodes for L-selectin in this study showed consistent diffuse moderate positivity of mantle zone lymphocytes (that is, mantle zone B cells), whereas
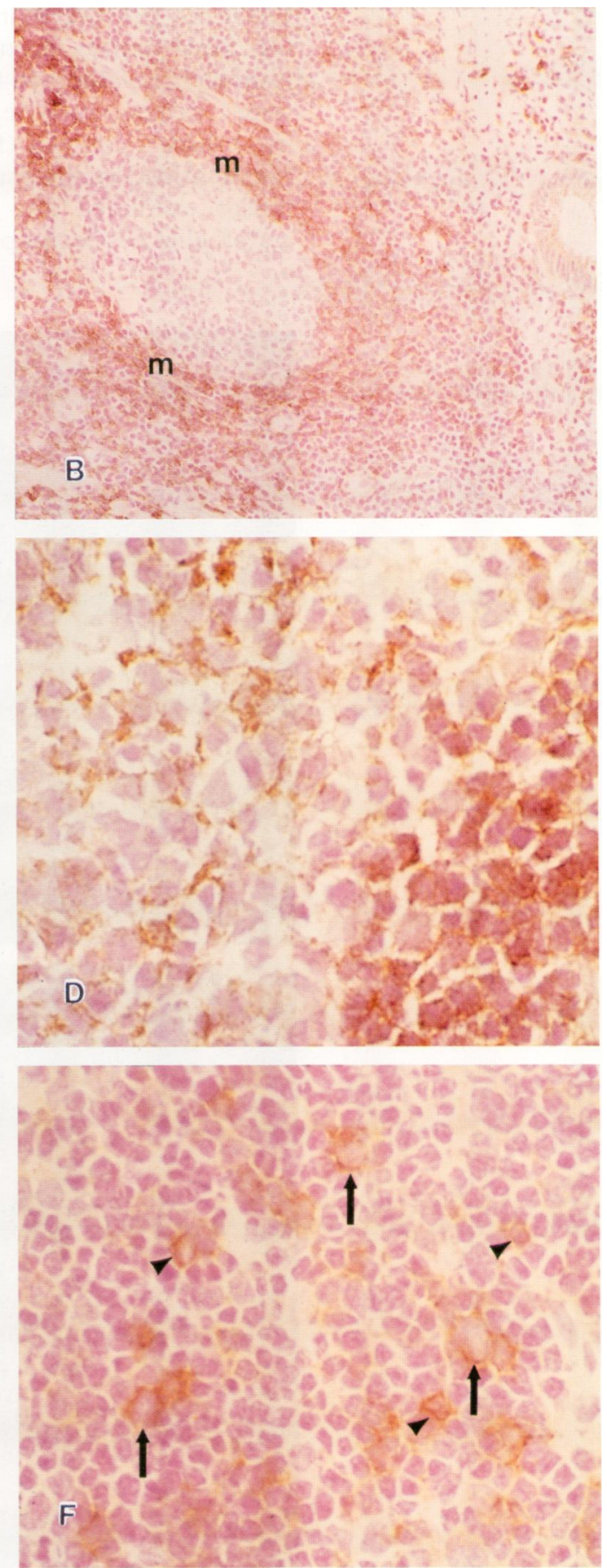

Figure 1 L-selectin expression in human lymphoid tissues (diaminobenzidine chromogen with haematoxylin counterstain $A-C \times 150, D-F \times 600)$. ( $A$ ) Peripheral lymph node follicle showing expression of $L$-selectin by mantle zone (m) $B$ cells. Positive cells are also seen in the interfollicular region (i). (B) Peyer's patch also showing expression in thin mantle zone (m) B cells. (C) Spleen with diffuse staining of white pulp lymphocytes, although fewer cells adjacent to (for example, to the left of) arteriole (a) are positive. (D) Follicular dendritic cell network expression of L-selectin in tonsil. Mantle zone

(showing $B$ cell staining) is at the bottom right. (E) Thymic medulla showing positive lymphocytes. (F) Occasional cortical thymocytes (arrowheads) and larger cells (macrophages; indicated by arrows) are positive for L-selectin. 
germinal centre B cells were negative (fig 1A). There was, however, weak L-selectin staining of follicular dendritic cells in one of five peripheral lymph nodes examined. Some cells with a lymphocytic morphology in the interfollicular zones of these tissues were also L-selectin positive. Intestinal lymphoid tissue showed uniform L-selectin positive mantle zone $B$ cells and negative germinal centre B cells (fig 1B). Splenic white pulp B cells were diffusely L-selectin positive (fig 1C), including in marginal zones, although only a small proportion of lymphocytes were positive in periarteriolar regions, a $T$ cell area. In the tonsillar specimens examined there were again L-selectin positive mantle zones in all cases. Germinal centres did not show positive B cell staining here, although follicular dendritic cells were $\mathrm{L}$-selectin positive in the light zones of all five tonsils examined (fig 1D). L-selectin was not identified on plasma cells. Three of the five tonsils examined also showed focal venular endothelial L-selectin positivity.
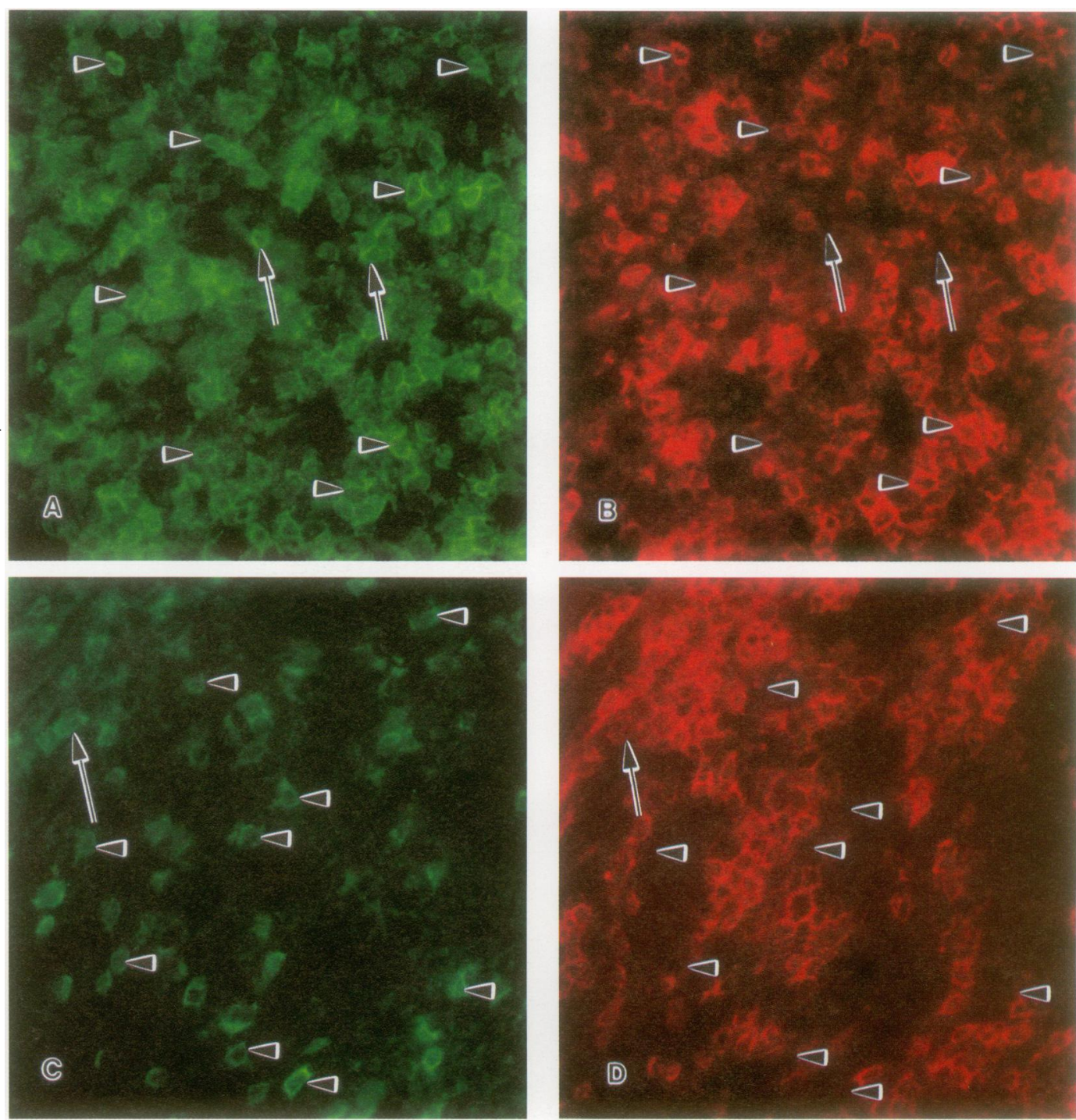

Figure 2 Two-colour immunofluorescence labelling of peripheral lymph node sections $(A, B)$ and Peyer's patch $(C, D)$ assessing expression of $C D 3(A, C)$ versus $L$-selectin $(B, D)($ all $\times 400) .(A) C D 3$ positive cells in a peripheral lymph node, some of which are identified by arrowheads and arrows. (B) Same section as $A$ showing many of these cells to be $L$-selectin positive (arrowheads), although not all are positive (for example, the cells indicated by arrows). (C) CD3 positive cells (arrowheads and arrow) in Peyer's patch adjacent to a mantle zone (centred on top left of panel). (D) Same section as in $C$ indicates that a large majority of the $T$ cells do not express $L$-selectin (arrowheads), although the cell indicated by the arrow does. 
Table 1 Percentage of CD45 positive leucocytes expressing $L$-selectin (mean $\pm S E M$ )

\begin{tabular}{lcr}
\hline Site & Non-inflamed & \multicolumn{1}{c}{ Inflamed } \\
\hline Skin & $0 \pm 0$ & $14.1 \pm 6.4$ \\
Appendix & $1.3 \pm 0.7$ & $3.6 \pm 1.4$ \\
Synovium & $0 \pm 0$ & $0.6 \pm 0.2$ \\
Kidney & $0.5 \pm 0.2$ & $30.2 \pm 9.8$ \\
\hline
\end{tabular}

mononuclear cells (table 1). Chronically inflamed skin, which contained infiltrates of $\mathrm{T}$ lymphocytes and macrophages, contained only a few cells that were weakly L-selectin positive. Acute appendicitis specimens showed accumulations of neutrophils, $T$ cells, and macrophages, but contained only occasional L-selectin positive infiltrating cells (fig 3), predominantly of a mononuclear nature. In one of the appendicitis specimens there was focal staining for L-selectin on the luminal aspect of venular endothelial cells. Inflamed (rheumatoid) synovium contained macrophages, $T$ cells, and a few B cells, but showed only very rare L-selectin positive mononuclear cells. Thus, the tissue specimens of inflamed skin, appendix, and synovium contained relatively few L-selectin positive leucocytes (table 1). In contrast, rejecting kidney transplants, which contained infiltrates of $\mathrm{T}$ lymphocytes and macrophages, contained a larger proportion of mononuclear cells that were L-selectin positive (table 1; fig 3). The nature of the cells expressing L-selectin was assessed by double fluorescence studies in rejecting kidney transplants. The results were that $89.1 \pm 4.7 \%$ of the

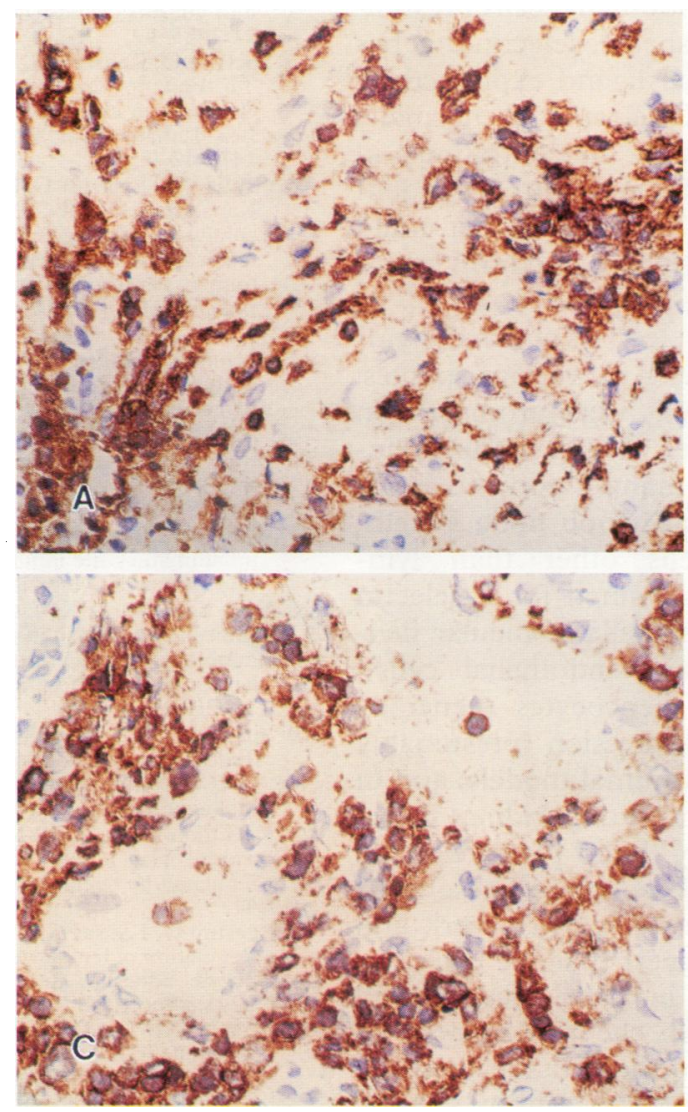

L-selectin positive cells expressed CD3 and 3.2 $\pm 1.0 \%$ expressed CD68.

\section{Discussion}

In the present study, we have evaluated the in vivo expression of $\mathrm{L}$-selectin in various human tissues. B lymphocytes were positive in the mantle zones within various lymphoid tissues, including both peripheral lymph nodes and mucosal lymphoid tissue. Lymphoid follicles are predominantly composed of $\mathbf{B}$ cells and their microanatomy reflects activational and proliferative events occurring here; the findings are in keeping with the concept that B cells initially migrate to the mantle zone and are subsequently present in the germinal centre in an activated state ${ }^{32}$ and shed L-selectin. Presumably memory B lymphocytes that would recirculate would be required to re-express $\mathrm{L}$-selectin, for which there is some in vitro evidence, ${ }^{33}$ prior to re-entry into peripheral lymph nodes. L-selectin was only expressed by a small proportion of cortical thymocytes, although expression was extensive by the time of migration to the medulla. While $\mathbf{B}$ cell expression within lymphoid follicles was comparable within peripheral versus mucosal lymphoid tissue (uniform expression by mantle zone B cells), the expression of $\mathrm{L}$-selectin by $\mathrm{T}$ lymphocytes showed characteristic differences between secondary lymphoid tissues, being relatively common in peripheral lymph nodes and lesser in intestinal lymphoid tissues or spleen. These findings regarding the distribu-
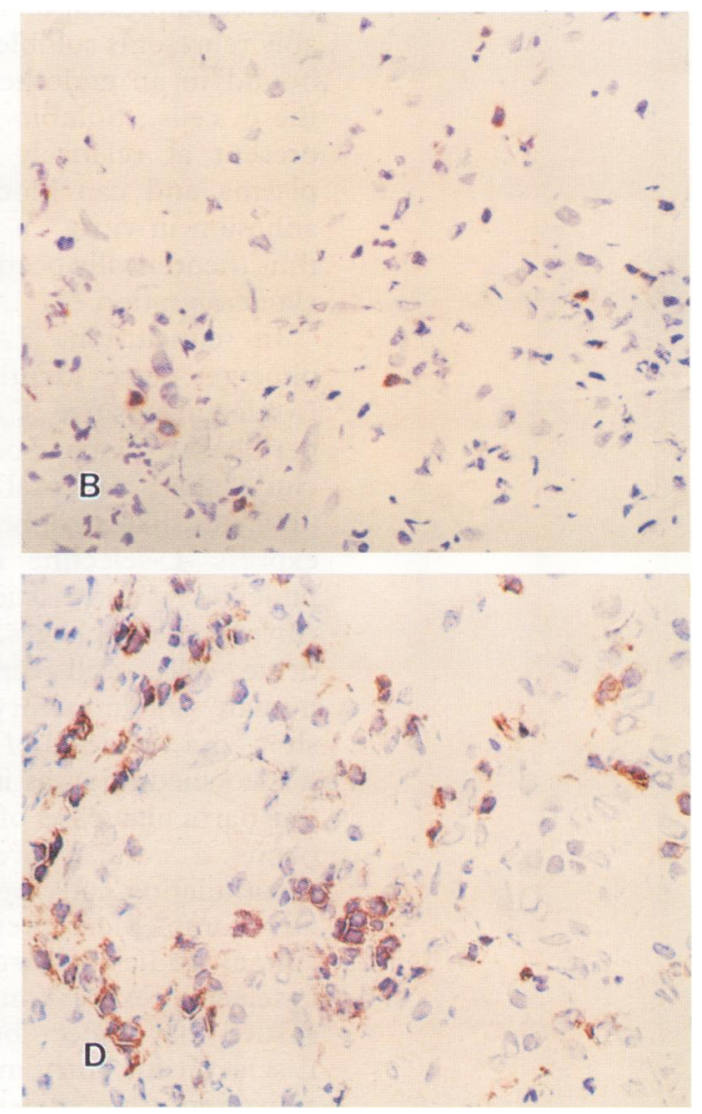

Figure 3 Antigen expression in inflamed appendix $(A, B)$ and kidney $(C, D)$. The total number of $C D 45$ positive leucocytes $(A, C)$ is compared with the number of cells expressing L-selectin $(B, D)$ (diaminobenzidine chromogen and haematoxylin counterstain, all $\times 300)$. (A) Numerous leucocytes are present in inflamed appendix wall, as identified by anti-CD45. (B) In a parallel section to $A$, only occasional cells express $L$-selectin. (C) Rejecting kidney transplant tissue assessed with anti-CD45. (D) In a parallel section to $C$, a higher proportion of cells express $L$-selectin. 
tion of these cells is consistent with a particular role of L-selectin in extravasation into peripheral lymph nodes, as described in animals. ${ }^{810}$

In most forms of inflammation studied, relatively few leucocytes within the inflamed tissue expressed L-selectin, consistent with shedding of this molecule upon activation. ${ }^{14}{ }^{19}$ Endoproteolytic release of L-selectin may occur at the time of leucocyte adhesion to endothelium, during emigration through vessels, after extravasation, or at combinations of these sites. These results suggest that downregulation of L-selectin through endoproteolytic release may play an important role in the inflammatory process, but further studies at the molecular level will be required to clarify exactly what this role is. However, a relatively large number of the emigrating leucocytes, in particular $\mathrm{T}$ lymphocytes, remained positive in rejecting renal transplants. The different proportion of inflammatory leucocytes that were L-selectin positive here could reflect recent arrival of the cells, their extravascular activation state, and/or some other factor, such as immunosuppressive treatment. In fact, a particular role has been ascribed to L-selectin in lymphocyte adhesion to endothelium during experimental allograft rejection. ${ }^{34}$

L-selectin expression in tissues in our studies was not restricted to lymphocytes. Interestingly, L-selectin was focally present on follicular dendritic cells, particularly in tonsils. It was also noted on thymic macrophages. Furthermore, L-selectin was observed on endothelial cells in tonsils and in one case of appendicitis. L-selectin present on endothelial cells presumably represents soluble/shed L-selectin that has bound to an endothelial ligand expressed by these cells. Soluble L-selectin is normally present at relatively high concentrations in plasma and can block L-selectin dependent adhesion in vitro, ${ }^{35}$ a phenomenon that could thus theoretically occur in vivo and limit leucocyte emigration.

In conclusion, L-selectin positive lymphocytes were identified in various tissues. L-selectin positive $T$ cells were prominent in peripheral lymph nodes. Novel findings include that: mucosal mantle zone B lymphocytes, like peripheral lymph node B cells, express L-selectin; cells other than lymphocytes within tissues stained for L-selectin (thymic macrophages, tonsillar follicular dendritic cells, and certain endothelial cells); human inflammatory leucocytes generally showed a low level of expression (presumably due to shedding), as in animal models; and in the particular case of rejecting kidney transplants a comparatively high proportion of accumulating cells were positive. These findings complement previous in vitro work and animal studies, and suggest that the extent of L-selectin expression in particular human tissues may reflect both the requirement of L-selectin for entry into those tissues and the activation state of leucocytes within specific microenvironments.

We gratefully acknowledge support by the Wellcome Trust (grant 036664/Z/92/Z to JMM) and National Institutes of
Health grants 5P30-HD-27805-0-03 (DMB), AI-26872, CA54464, HL-50985 (TFT). DMB is also supported by a Janeway Award of the Children's Hospital and TFT is a Scholar of the Leukemia Society of America. We thank Clive Collett for technical assistance.

1 Stamper HB Jr, Woodruff JJ. Lymphocyte homing into ymph nodes: in vitro demonstration of the selective affinity of recirculating lymphocytes for high-endothelial venules. 7 Exp Med 1976;144:828-33.

2 Springer TA. Traffic signals for lymphocyte recirculation and leukocyte emigration: The multistep paradigm. Cell $\Rightarrow$ 1994;76:301-14.

3 Tedder TF, Isaacs CM, Ernst TJ, Demetri GD, Adler DA, Disteche CM. Isolation and chromosomal localization of CDNAs encoding a novel lymphocyte cell surface molecule, LAM-1. F Exp Med 1989;170:123-33.

4 Tedder TF, Penta A, Levine HB, Freedman AS. Expression of the human leukocyte adhesion molecule, LAM-1: Iden- 2 tity with the TQ1 and Leu-8 differentiation antigens. $F$ ल
Immunol 1990;144:532-40.

5 Spertini O, Luscinskas FW, Kansas GS, Munro JM, Griffin $\vec{\circ}$ JD, Gimbrone MA Jr, Tedder TF. Leukocyte adhesion. molecule-1 (LAM-1, L-selectin) interacts with an inducible endothelial cell ligand to support leukocyte adhesion. f Immunol 1991;147:2565-2537.

6 Ley K, Tedder TF, Kansas GS. L-selectin can mediate leu- $\overrightarrow{0}$ kocyte rolling in untreated mesenteric venules in vivo independent of E- or P-selectin. Blood 1993;82:1632-8.

7 Siegelman MH, van de Rijn M, Weissman IL. Mouse lymph io node homing receptor cDNA clone encodes a glycoprotein revealing tandem interaction domains. Science 1989; $N$ 243:1165-72.

8 Gallatin WM, Weissman IL, Butcher EC. A cell-surface 음 molecule involved in organ-specific homing of lymphocytes. Nature 1983;304:30-4

9 Holzmann B, McIntyre BW, Weissman IL. Identification of a murine Peyer's patch-specific lymphocyte homing recep- $O$ tor as an integrin molecule with an $\alpha$ chain homologous to human VLA-4 $\alpha$. Cell 1989;56:37-46.

10 Arbones ML, Ord DC, Ley K, Radich H, Maynard-Curry C, Capon DJ, Tedder TF. Lymphocyte homing and leukocyte rolling and migration are impaired in L-selectin (CD62L) deficient mice. Immunity 1994;1:247-60.

11 Bargatze RF, Wu NW, Weissman IL, Butcher EC. High oै endothelial venule binding as a predictor of the dissemina tion of passaged murine lymphomas. $\mathcal{F}$ Exp Med 1987; 166: 1125-31.

12 Hamann A, Jablonski-Westrich D, Jonas $P$, Thiele $H-G$. Homing receptors reexamined: mouse LECAM-1 (MEL-14 antigen) is involved in lymphocyte migration into gut-associated lymphoid tissue. Eur 7 Immunol 1991; into gut-ass

13 Spertini O, Kansas GS, Reimann KA, Mackay CR, Tedder $\overrightarrow{\overrightarrow{0}}$ TF. Function and evolutionary conservation of distinct epitopes on the leukocyte adhesion molecule-1 (TQ-1, Leu-8) that regulate leukocyte migration. F Immunol 1991; 147:942-9.

14 Griffin JD, Spertini O, Ernst TJ, Belvin MP, Levine HB, Kanakura Y, Tedder TF. Granulocyte-macrophage $\overline{0}$ colony-stimulating factor and other cytokines regulate surface expression of the leukocyte adhesion molecule- 1 on human neutrophils, monocytes, and their precursors. $\mathcal{F}$ Immunol 1990;145:576-84.

15 Spertini O, Luscinskas FW, Gimbrone MA Jr, Tedder TF. O Monocyte attachment to activated human vascular en- $\supsetneq$ dothelium in vitro is mediated by Leukocyte Adhesion 0 Molecule-1 (L-selectin) under non-static conditions. f Exp $\mathrm{O}$ Med 1992;175:1789-92.

16 Munro JM. Endothelial-leukocyte adhesive interactions in 을 inflammatory diseases. Eur Heart $\mathcal{f}$ 1993;14(Suppl K):72-7.

17 Watson SR, Fennie C, Lasky LA. Neutrophil influx into an inflammatory site inhibited by a soluble homing receptorIgG chimaera. Nature 1992;349:164-7.

18 Yang X-D, Karin N, Tisch R, Steinman L, McDevitt HO. $\omega$ Inhibition of insulitis and prevention of diabetes in $\sigma$ nonobese diabetic mice by blocking $L$-selectin and very late antigen 4 adhesion receptors. Proc Natl Acad Sci USA late antigen 4 adhesio:

19 Spertini O, Freedman AS, Belvin MP, Penta AC, Griffin JD, 巫 Tedder TF. Regulation of leukocyte adhesion molecule-1 (TQ1, Leu-8) expresion and shedding by normal and malignant cells. Leukemia 1991;5:300-8.

20 Kishimoto TK, Jutila MA, Berg EL, Butcher EC. Neutrophil Mac-1 and MEL-14 adhesion proteins inversely regulated by chemotactic factors. Science $1989 ; 245: 1238$ 41.

21 Spertini O, Kansas GS, Munro JM, Griffin JD, Tedder TF. Regulation of leukocyte migration by activation of the leukocyte adhesion molecule-1 (LAM-1) selectin. Nature 1991;349:691-4.

22 Munro JM, Lo SK, Corless C, Robertson MJ, Lee NC, Barnhill RL, et al. Expression of sialyl-Lewis $\mathrm{X}$, an E-selectin ligand, in inflammation, immune processes, and lymphoid tissues. Am $\mathcal{f}$ Pathol 1992;141:1397-408.

23 Imai Y, Lasky LA, Rosen SD. Sulphation requirement for GlyCAM-1, an endothelial ligand for L-selectin. Nature 1993;361:555-7.

24 Lasky LA, Singer MS, Dowbenko D, Imai Y, Henzel WJ, Grimley C, et al. An endothelial ligand for L-selectin is a novel mucin-like molecule. Cell 1992;69:927-38. 
25 Baumhueter S, Singer MS, Henzel W, Hemmerich S, Renz $M$, Rosen SD, Lasky LA. Binding of L-selectin to the vascular sialomucin CD34. Science 1993;262:436-8.

26 Berg EL, McEvov LM, Berlin C, Bargatze RF, Butcher EC. L-selectin-mediated lymphocyte rolling on MAdCAM-1. Nature 1993;366:695-8.

27 Häaninen A, Taylor C, Streeter P, Stark LS, Sarte JM, Shizuru JA, et al. Vascular addressins are induced on islet vessels during insulitis in nonobese diabetic mice and are involved in lymphoid cell binding to islet endothelium. $\mathcal{F}$ Clin Invest 1993;92:2509-15.

28 Kansas GS, Wood GS, Fishwild DM, Engleman EG. Functional characterization of human $\mathrm{T}$ lymphocyte subsets distinguished by monoclonal anti-Leu-8. $\mathcal{F}$ Immunol 1985; 134:2995-3002.

29 Pallesen G, Knudsen LM. Leucocyte antigens in human post mortem tissues: their preservation and loss demonpost mortem tissues: their preservation and loss demon-
strated by monoclonal antibody immunohistological stainstrated by monoclonal antibody imm
ing. Histopathology 1985;9:791-804.

30 Munro JM, Freedman AS, Aster JC, Gribben JG, Lee NC, Rhynhart KK, et al. In vivo expression of the B7 costimu- latory molecule by subsets of antigen-presenting cells and the malignant cells of Hodgkin's disease. Blood 1994; 83:793-8.

31 Weiss LM, Arber DA, Chang KL. CD68: A review. Applied Immunohistochemistry 1994;2:2-8.

32 Nieuwenhuis P, Ford WL. Comparative migration of B- and T-lymphocytes in the rat spleen and lymph nodes. Cell Immunol 1976;23:254-67.

33 Kraal G, Weissman, Butcher EC. Memory B cells express a phenotype consistent with migratory competence after secondary but not short-term primary immunization. Cell Immunol 1988;115:78-87.

34 Turunen JP, Paavonen T, Majuri M-L, Tiisala S, Mattila P, Mennander A, et al. Sialyl Lewis ${ }^{\mathrm{x}}$ - and L-selectindependent site-specific lymphocyte extravasation into renal transplants during acute rejection. Eur 7 Immunol 1994;24:1130-6.

35 Schleiffenbaum B, Spertini O, Tedder TF. Soluble L-selectin is present in plasma at high levels and retains functional activity. $\mathcal{F}$ Cell Biol 1992;119:229-38. 